\title{
Effect of simultaneous auditory stimulation on vibrotactile thresholds*
}

\author{
RONALD T. VERRILLO and ANTHONY J. CAPRARO \\ Institute for Sensory Research, Syracuse University, Merrill Lane, Syracuse, New York 13210
}

\begin{abstract}
Vibrotactile thresholds were determined at 250 and $400 \mathrm{~Hz}$ in the presence of (1) the sounds emitted by the vibrator, (2) continuous tonal or narrow-band masking noise, or (3) a pulsed tone synchronized with the vibrator signal. The measure of a cross-modality effect was the threshold shift occurring between each condition and the control condition, in which earmuff silencers eliminated the vibrator sounds. Continuous tones or noise had no effect upon vibrotactile thresholds. However, auditory signals synchronized with the vibrator signals did significantly elevate vibrotactile thresholds.
\end{abstract}

The phenomenon of sensory interaction has been the object of extensive investigation and the subject of several comprehensive literature reviews (Ryan, 1940; Loveless, Brebner, \& Hamilton, 1970). By sensory interaction, we mean the effect upon a sensory channel of the simultaneous input of a signal into a second sensory channel. The early literature concerned itself primarily with the question of how thresholds may be modified as a result of bisensory presentation of stimuli. More recently, the focus of investigation has shifted to an assessment of the benefits that might derive from the simultaneous use of several information channels (Loveless et al, 1970). Our interest in this study lies with the earlier question: the effect upon vibrotactile thresholds of accessory auditory stimulation. The overwhelming bulk of research has concentrated, however, on the interaction of hearing and vision, leaving a paucity of information regarding the interaction of vibrotaction with other sense modalities.

The findings of previous studies are by no means unequivocal. Cason (1936), Brogden (1950), Brogden and Gregg (1951), and Gregg and Brogden (1952) all showed small, but significant, improvements in sensitivity of auditory thresholds as a result of simultaneous visual stimulation. Symons (1963) lowered visual thresholds by the heteromodal stimulation of olfactory, gustatory, auditory, thermal, and proprioceptive systems. $\mathrm{He}$ postulates a "priming" effect via the reticular formation. Maruyama (1961) and Givotti and Peri (1963) found both increased and decreased sensitivity, depending upon the frequency of the auditory stimulus and the site of stimulation upon the retina. Both papers postulate specific neural interactions between the two sensory systems. Brown and Hopkins (1967) improved

*This research was supported by Grant NS-09940 from the National Institutes of Health, U.S. Department of Health, Education and Welfare. signal-detection performance using auditory and visual stimulation, but concluded that there was no apparent interaction between the two systems, since their results could be accounted for by the simple probabilistic adding of information from two independent sense channels. Thompson, Voss, and Brogden (1958), Gulick and Smith (1959), and Davis (1966), on the other hand, report decreases in sensitivity in hearing and vision as a result of bisensory stimulation. Again, the effects are small and tend to diminish in time.

Gardner and Licklider (1959) demonstrated that intense acoustic stimulation acted as an analgesic agent in dental surgery, but Licklider (1961) cautioned that these were clinical observations and recognized the difficulty of achieving dramatic effects in the laboratory. Howitt and Stricker (1966), using an auditory masker whose onset preceded the signal by $1 \mathrm{sec}$, were unable to show an increase in pain thresholds or tolerance to electrostimulation of the tooth pulp. Other studies have been unable to demonstrate that auditory maskers are effective in reducing pain (Carlin, Ward, Gershon, \& Ingraham, 1962; Camp, Martin, \& Chapman, 1962) or taste thresholds (McFadden, Barr, \& Young, 1971).

There are few studies concerned with the interaction between the auditory and tactile systems. This is somewhat surprising, since the elimination of audible sounds emitted by the vibrator has always been considered a problem in vibrotactile experiments. Attempts to cope with the problem have usually involved the addition of an auditory masking stimulus. These include masking the unwanted sound by stimulating with a variety of auditory inputs such as white noise (Goff, 1967), pure tones (Talbot, Darian-Smith, Kornhuber, \& Mountcastle, 1968), or narrow-band noise (Verrillo, Fraioli, \& Smith, 1969). Attenuation of sound by the use of earmuffs has also been reported (Verrillo, 1962). Although the sound emitted by the vibrator is generally considered to be 
undesirable, its effect on vibrotactile thresholds has never been firmly establilshed. Early studies involved either electrocutaneous stimulation or static pressure (Loveless et al, 1970) and have little bearing upon the problem.

The first systematic study of vibrotactile-auditory cross-modality effects was reported by Gescheider and Niblette (1967). They considered the temporal patterning of both the signal and masker and showed that the threshold for a cutaneous signal (short vibratory pulses) can be increased by an auditory masker (clicks) if the auditory stimulus is both intermittent and closely correlated with the occurrence of the signal. The use of earphones made the clicks from the vibrator inaudible. In a later study (Gescheider, Barton, Bruce, Goldberg, \& Greenspan, 1969), relatively small decrements in vibrotactile sensitivity were produced by an auditory masker. Gescheider et al showed that the effect could be influenced by instructions to the $S s$ and that it tended to diminish with time. They offer an explanation of the effect which involves the habituation of neural responses within the auditory system and the activation of the reticular formation. Gescheider, Herman, and Phillips (1970) reported vibrotactile threshold increments in the presence of auditory clicks when measured either by a tracking or a forced choice psychophysical method. A greater effect was produced by the tracking method. At a masking level of $60 \mathrm{~dB} \mathrm{SL}$, they report an increment in the vibrotactile threshold of approximately $3 \mathrm{~dB}$ for the tracking method and approximately $1.0 \mathrm{~dB}$ for the forced choice method. The loss of vibrotactile sensitivity was proportional to the intensity of the auditory masker.

The purpose of the present investigation is to determine the effect of auditory signals upon the vibrotactile threshold of detectability. The effect of continuous vs pulsed maskers and the effect of the frequency characteristic of the masker will be considered.

\section{METHOD}

Vibratory stimulation was delivered by a Goodman's 390-A vibrator. The $\mathrm{S}$ and vibrator assembly were located in a soundproofed booth. Sinusoidal signals were generated by an oscillator and fed into a set of Grason-Stadler switches set to give a rise-fall time of $50 \mathrm{msec}$. The time pattern $(600 \mathrm{msec}$ on $1,400 \mathrm{msec}$ off) was controlled by Tektronix timing generators. The signal was then emplified by a General Radio unit amplifier, passed through an impedance matching transformer, and amplified by a Kepco power amplifier before being delivered to the vibrator. The intensity of the signal could be adjusted by means of a $120-\mathrm{dB}$ step attenuator, controlled by the $E$, and a Békésy tracking attenuator, operated by the $\mathrm{S}$.

The $S$ placed the thenar area of his palm on a rigid surface over a vibrator located on a drill press platten (Verrillo, 1966). The contactor $\left(2.9 \mathrm{~cm}^{2}\right)$ protruded into a hole within a rigid surround, leaving a $1-\mathrm{mm}$ gap between contactor and surround. The contactor was adjusted so that it pressed $0.5 \mathrm{~mm}$ into the skin. Vibratory displacement was calculated from the output of an Endevco accelerometer system mounted on the moving element of the vibrator. Thresholds were determined in one testing session with the aid of a Békésy tracking attenuator. The tracking period for each condition lasted from 4 to 5 min.

The auditory noise was generated by a Grason-Stadler noise generator; its bandwidth was determined by adjusting an Allison filter. The auditory tone was generated by another oscillator. Both the tone and the noise were switched, amplified, impedance matched, and attenuated by a network similar to that used for the vibratory stimulus. The auditory stimulus was delivered to the $S$ through a set of Grason-Stadler TDH-39 headphones.

Vibrotactile thresholds were determined at both 250 and $400 \mathrm{~Hz}$ for each of four experimental conditions of auditory stimulation and a control condition. The first condition used a continuous narrow-band noise centered around the frequency of the vibratory stimulus $(240-270 \mathrm{~Hz}$ for $250-\mathrm{Hz}$ vibration, and $360-450 \mathrm{~Hz}$ for $400-\mathrm{Hz}$ vibration). The second condition used a continuous pure tone identical to the frequency of vibrotactile stimulation. In the third condition, a pure tone, identical to the frequency of vibrotactile stimulation $(250 \mathrm{~Hz}$ only), was pulsed to coincide with the occurrence of the vibratory stimulus. No attempt was made to mask or muffle the airborne sound in the fourth condition, allowing the $S$ to hear any sound emitted by the vibrator. This will be referred to as the open condition. The fifth, or control, condition consisted of using earmuffs (MSA Noisefoe) to eliminate the sound emitted by the vibrator.

The five conditions at each frequency were presented in a random sequence to each of six Ss, all of whom had had previous experience with tracking thresholds. The intensity of the narrow-band masking noise and of the masking tone was set at 60-dB sensation level (SL), as determined individually for each $S$.

\section{RESULTS}

The mean threshold measurements for six Ss obtained at two frequencies for each of the five experimental conditions are shown in Table 1. The data are reported in decibels referred to 1.0 micron of peak displacement. The effect of the auditory stimulation upon vibrotactile thresholds is expressed as "Threshold Shift" in Table 1 . It was determined by comparing the vibrotactile threshold obtained in each experimental condition with that of the control condition at each frequency.

A randomized block design analysis of variance (Edwards, 1960) was performed for the $400-\mathrm{Hz}$ data

Table 1

Mean Thresholds and Threshold Shifts in Decibels Referred * to 1.0 Micron of Peak Displacement

\begin{tabular}{|c|c|c|c|c|}
\hline \multirow[b]{2}{*}{$\begin{array}{c}\text { Experimental } \\
\text { Condition }\end{array}$} & \multicolumn{2}{|c|}{ 250-Hz Frequency } & \multicolumn{2}{|c|}{ 400-Hz Frequency } \\
\hline & $\begin{array}{l}\text { Mean } \\
\text { Thres- } \\
\text { hold }\end{array}$ & $\begin{array}{l}\text { Thres- } \\
\text { hold } \dagger \\
\text { Shift }\end{array}$ & $\begin{array}{l}\text { Mean } \\
\text { Thres- } \\
\text { hold }\end{array}$ & $\begin{array}{l}\text { Thres- } \\
\text { hold } \dagger \\
\text { Shift }\end{array}$ \\
\hline Control & -17.8 & & -15.6 & \\
\hline $\begin{array}{l}\text { Continuous } \\
\text { Narrow Band }\end{array}$ & -17.6 & +.2 & -16.3 & +.6 \\
\hline Continuous Tone & -17.7 & +.1 & -15.1 & +.5 \\
\hline Pulsed Tone & -13.8 & $+4.0^{*}$ & & \\
\hline Open & -15.4 & $+2.4^{*}$ & -14.0 & $+1.6 *$ \\
\hline
\end{tabular}

tDeparture of experimental thresholds from control condition. ${ }^{*}$ Significant at $p<.05$ or beyond. 
and two analyses were performed for the $250-\mathrm{Hz}$ data: one in which the pulsed-tone condition was included and another which included the open condition. The analysis showed the variance for the $400-\mathrm{Hz}$ data to be significant at the .01 level of confidence, and for both analyses of the $250-\mathrm{Hz}$ data, a .05 level of significance was reached.

Following the analysis of variance, the threshold shifts were tested for significance using Dunnett's test (Dunnett, 1955; Edwards, 1960), which yielded levels of significance comparable to the analyses of variance. At $400 \mathrm{~Hz}$, when the control condition was compared to the open condition, a significant threshold shift was recorded $(p<.005)$, and at $250 \mathrm{~Hz}$, a significant shift occurred between the control and open conditions $(\mathrm{p}<.05)$ and also between the control and pulsed-tone conditions $(\mathrm{p}<.005)$.

Since the cutaneous literature (taction and pain) indicates that bimodality stimulation results either in no threshold shift or a decrement in sensitivity, we felt that a one-tailed test of significance was indicated. Our threshold shifts showed a decrement in vibratory sensitivity in the presence of pulsed auditory signals. The application of two-tailed tests does not alter the results shown in Table 1 except that, at $250 \mathrm{~Hz}$, the significance level for open vs control approached, but did not reach, the .05 level. The standard deviations ranged from 5.6 (open-250 Hz) to 9.4 (continuous narrow band- $400 \mathrm{~Hz}$ ).

Vibrotactile thresholds measured with continuous auditory noise or continuous-tone maskers resulted in only slight shifts from those measured under the control condition. The largest effects occurred when no attempt was made to eliminate the sound emitted by the vibrator $(250$ and $400 \mathrm{~Hz})$ or when a pulsed tone $(250 \mathrm{~Hz})$ was used. Thresholds at $400 \mathrm{~Hz}$ were not measured in the preence of a $400-\mathrm{Hz}$ pulsed masker because, at this frequency, the sound emitted by the vibrator was clearly audible in the open condition. Since the threshold shift at $400 \mathrm{~Hz}$ in the open condition was significant, it was not considered necessary to repeat the measurement using a $400-\mathrm{Hz}$ pulsed masker delivered through earphones.

\section{DISCUSSION}

It is clear that auditory maskers, pure tone or narrow-band noise, do not affect vibrotactile thresholds significantly when the masker is presented continuously. A decrease in sensitivity is apparent, however, when the masker is synchronized with the vibratory stimulus. The effect is present either when the $\mathrm{S}$ can hear the sound emitted by the vibrator or when a simultaneous pulsed tone is delivered through earphones.

In our experiments, the cross-modality effect was most pronounced when the threshold for a $250-\mathrm{Hz}$ vibration was determined in the presence of a $250-\mathrm{Hz}$ pulsed auditory masker at an intensity level of $60 \mathrm{~dB}$ SL. In the open condition, the sound emitted by the vibrator at 400 and $250 \mathrm{~Hz}$ resulted in a small, but significant, decrease in vibrotactile sensitivity. Thus, auditory stimuli elevated vibrotactile thresholds most in the synchronous pulsed-tone condition, less in the open condition at $250 \mathrm{~Hz}$, and least in the open condition at $400 \mathrm{~Hz}$.

The results in part agree and in part disagree with recent studies on cross-modality masking. Consistent with the audio analgesia study of Carlin, Ward, Gershon, and Ingraham (1962), who used a continuous masker, we find that continuous masking tones or narrow-band noise of moderately high intensity $(60 \mathrm{~dB} \mathrm{SL})$ have an extremely small effect on vibrotactile thresholds. However, the threshold shifts obtained when the vibrator sound was audible or when a pulsed-tone masker was used conflict with reports of no cross-modality effects using intermittent maskers (Howitt \& Stricker, 1966; McFadden, Barr, \& Young, 1971). It should be noted that in those studies showing no effect, the pulsed auditory signal preceded the vibratory signal by $1-5 \mathrm{sec}$. It is reasonable to conclude that the time sequence was responsible for the absence of any effect, since Gescheider and Niblette (1967) demonstrated a sharp decrease in cross-modality masking as the auditory signal preceded or followed the vibratory signal by as little as $50 \mathrm{msec}$. For simultaneous masker and signa1, our results are consistent with those of Gescheider and Niblette. Studies showing no effect may be explained by the time delay between the auditory masker and the vibratory signal.

The masking of unwanted sounds from the vibrator becomes particularly difficult when suprathreshold stimulation is required, as in magnitude scaling experiments. At the present time, nothing is known regarding the effect of hearing vibrator sounds upon the performance of $S s$ in magnitude estimation or production experiments. The importance of determining such effects is emphasized by the finding that the largest threshold shift occurred when a pulsed auditory tone $(250 \mathrm{~Hz})$ was presented at a fairly high intensity level (60 dB SL). Measurements were made of the sound intensities emitted by the vibrator at vibrotactile threshold levels at both frequencies. Because of the variation in the vibrotactile thresholds, these data did not lend themselves readily to a statistical analysis. It was obvious, however, that the audible signals in the open conditions were considerably less than $60 \mathrm{~dB} \mathrm{SL}$. Although it was not studied systematically, the data show an elevation in vibrotactile thresholds as the intensity of the auditory signal increased (Gescheider \& Niblette, 1967; Gescheider et al, 1970). The finding emphasizes the need to know what cross-modality effects exist at suprathreshold levels of vibrotactile stimulation. 
Our results are consistent with those studies that show small increments in vibrotactile thresholds in the presence of pulsed auditory maskers. It is not possible, on the basis of our experiments, to decide whether the effect was the result of specific neural connections between modalities or a decrement of attention due to a competing sensory input. Since our instructions neither emphasized nor deemphasized the presence of the masker, we cannot comment on the effect that Gescheider et al (1969) report. They suspected that the small intermodality effect was obtained because of specific instructions to ignore the auditory signals. In our case, specific instructions might have reduced variability in the data but it is impossible to say if it would have altered the general results.

For practical purposes, we may conclude that audible airborne sounds from the vibrator may significantly elevate detection thresholds for vibration. The sizes of the threshold shifts are not large in absolute terms and may be tolerated depending on the requirements of the experiment. When precise measurements are called for, however, it is obvious that earmuffs or auditory maskers should be used to eliminate the sound from the vibrator.

\section{REFERENCES}

Brogden, W. J. Sensory conditioning measured by the facilitation of auditory acuity. Journal of Experimental Psychology, 1950, 40, 512-5!9.

Brogden, W. 1., \& Gregg, L. W. Studies of sensory conditioning measurec by the facilitation of auditory acuity. Journal of Experimental Psychology, 1951, 42, 384-389.

BRown, A. E., \& Hopkins, H. K. Interaction of the auditory and visual sense modalities. Journal of the Acoustical Society of America, 1967, 41, 1-6.

Camp, W., Martin, R., \& Chapman, L. F. Pain threshold and discrimination of pain intensity during brief exposure to intense noise. Science, 1962, 135, 788-789.

Carlin, S., Ward, W. D., Gershon, A., \& Ingraham, R. Sound stimulation and its effect on dental sensation threshold. Science, 1962, 138, 1258-1259.

CAson, H. Sensory conditioning. Journal of Experimental Psychology, 1936, 19, 572-593.

Davis, E. T. Heteromodal effects upon visual thresholds. Psychological Monographs, 1966, 80(24, Whole No. 632).

DunNetT, C. W. A multiple comparison procedure for comparing several treatments with a control. Journal of the American Statistical Association, 1955, 50, 1096-1121.

EDWARDS, A. L. Experimental design in psychological research. New York: Rinehart, 1960.

Gardner, W. J., \& Licklider, J. C. R. Serendipitous effects of masking noise upon sensations produced by the dentists's drill. Journal of the Acoustical Society of America, $1959,31,850$.
Gescheider, G. A., Barton, W. G., Bruce, M. R., Goldberg, J. H., \& GreENSPAN, M. J. Effects of simultaneous auditory stimulation on the detection of tactile stimuli. Journal of Experinental Psychology, 1969, 81, 120-125.

Gescheider, G. A., Herman, D. D., \& Phillips, J. N. Criterion shifts in the measurement of tactile masking. Perception \& Psychophysics, 1970, 8, 433-436.

Gescheider, G. A., \& Niblette, R. K. Cross-modality masking for touch and hearing. Journal of Experimental Psychology, $1967,77,308-313$.

Givotri, G., \& Peri, G. Selective effects of monoauricular stimulation upon extrafoveal visual acuity. Archivo di Psicologia. Neurologia i Psichiatria, 1963, 24, 265-288.

GofF, G. D. Differential discrimination of frequency of cutaneous mechanical vibration. Journal of Experimental Psychology, 1967, 74, 294-299.

GREGG, L. W., \& BROGDEN, W. J. The effect of simultaneous visual stimulation on absolute auditory sensitivity. Journal of Experinental Psychology, 1952, 43, 179-186.

Gulick, W. L. \& Smith, F. L. The effect of intensity of visual stimulation upon auditory acuity. Psychological Record, 1959, 9. 29-32.

Howitr, J. W., \& STricker, G. Objective evaluation of audio analgesia effects. Journal of the American Dental Association, $1966,73,874-877$.

Licklider, J. C. R. On psychophysiological models. In W. A. Rosenbith (Ed.), Sensory communication. New York: M.I.T. Press and Wiley, 1961.

Loveless, N. E., Brebner, J., \& Hamilton, P. Bisensory presentation of information. Psychological Bulletin, 1970, 73, 161-199.

McFadden, D., Barr, A. E., \& Young, R. E. Audio analgesia: Lack of a cross-masking effect on taste. Perception \& Psychophysics, 1971, 10, 175-179.

MaruYama, K. "Contralateral relationship" between the ears and the halves of the visual field in sensory interaction. Tohoku Psychologica Folia, 1961, 19, 81-92.

RYAN, T. A. Interrelations of sensory systems in perception. Psychological Bulletin, 1940, 37, 659-698.

Symons, J. R. The effect of various heteromodal stimuli on visual sensitivity. Quarterly Journal of Experimental Psychology, 1963, 15, 243-251.

Talbot, W. H., Darian-Smith, I., Kornguber, H. H., \& Mountcastle, V. B. The sense of flutter-vibration: Comparison of the human capacity with response patterns of mechanoreceptive afferents from the monkey hand. Journal of Neurophysiology, 1968, 31, 301-334.

Thompson, R. F., Voss, J. F., \& Brogden, W. J. Effect of brightness of simultaneous visual stimulation on absolute auditory sensitivity. Joumal of Experimental Psychology, 1958, 55, 45-50.

VERRILLO, R. T. Investigation of some parameters of the cutaneous threshold for vibration. Journal of the Acoustical Society of America, 1962, 34, 1768-1773.

Verrillo, R. T. Effect of spatial parameters on the vibrotactile threshold. Journal of Experimental Psychology, 1966, 71, 570-575.

Verrillo, R. T., Fraioli, A., \& SMith, R. Sensation magnitude of vibrotactile stimuli. Perception \& Psychophysics, 1969, 6, 366-372.

(Received for publication January 25, 1974; revision received July 18,1974 .) 